\title{
ASSESSMENT OF THE ROADWAY DYNAMIC RESPONSE DUE TO THE TATRA 815 LORRY EXCITATION AND EXPERIMENTAL VERIFICATION
}

The effect of moving load represents the current problem which is analyzed in engineering practice. The response of the vehicle and its dynamic effect on the pavement can be analyzed in an experimental or computational way. The road-vehicle interaction effect is one of the most important problems for the vibration propagation due to traffic. This paper shows the practical analysis of the Tatra 815 Lorry passing effect using two software systems based on the Finite Element Method (FEM). First system is better for a vehicle model and its passing on a simple road model based on Winkler-Pasternak theory of elastic half-space. In the second system, the vehicle model is not supported but it is better and more accurate for the road and geological environment model - where the subsoil layers were modeled separately. The computing is carried out in time domain. The results obtained by the FEM simulation are compared with the result obtained by the experiment in frequency domain.

Keywords: Finite element method, dynamic analysis, vibration propagation, time domain, frequency domain

\section{Introduction}

The heavy road vehicles are at present one of the induced seismicity sources. The moving load generates vibrations which are propagated in geological environment. The assessment of the vibration effect can be performed numerically (FEM dynamic numerical analysis) or it can be experimentally extrapolated. For the FEM dynamic solution many commercial computing systems are currently available. Every system is comfortable for different analysis. That is the reason for a more difficult analysis of decomposition to subsystems. Each system is conformably modeled. In this case (road dynamic response due to vehicle passing) the MODEL 1 (M1) is created in ADINA system. Subsystem of MODEL 2 (M2) is used in Visual FEA for the roadsoil dynamic response.

\section{Dynamic Simulation of the Tatra 815 Lorry Moving Load - M1}

For M1 model it is necessary to describe the basic vehicle and road technical parameters. This model is planar and interactive. It is also necessary to define the basic mathematical principles of the ADINA system.

\subsection{Description of the Tatra 815 Half-Part Model}

One of the most important parts of the process of numerical simulation is to create a proper computing model. For this case the half-part model of the TATRA 815 was chosen as the most representative vehicle (Fig. 1). The theoretical solution is based on the FEM. The FEM has been mostly used since computer calculations started as one of the possible ways to find solution to systems of differential equations. In this particular case the vehicle was moving steadily on the pavement. These actions are described by the following differential equation:

$[\mathrm{M}] \cdot\{\ddot{\mathrm{u}}(\mathrm{t})\}+[\mathrm{C}] \cdot\{\dot{\mathrm{u}}(\mathrm{t})\}+[\mathrm{K}] \cdot\{\mathrm{u}(\mathrm{t})\}=\{\mathrm{F}(\mathrm{t})\}$,

where $[\mathrm{M}],[\mathrm{C}]$ and $[\mathrm{K}]$ are mass, damping and stiffness matrices.

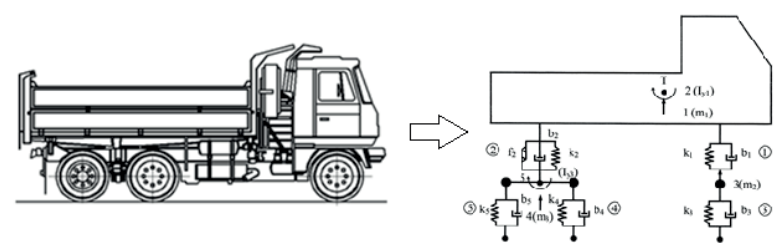

Fig. 1 Half-part model of the lorry T-815

\footnotetext{
* 'Veronika Valaskova, ${ }^{1}$ Daniel Papan, ${ }^{2}$ Rui C. Barros

${ }^{1}$ Department of Structural Mechanics and Applied Mathematics, Faculty of Civil Engineering, University of Zilina, Slovakia

${ }^{2}$ Department of Civil Engineering, Structural Division, FEUP - Faculty of Engineering of the University of Porto, Portugal

E-mail: veronika.valaskova@fstav.uniza.sk
} 
Important part of simulation is to choose the appropriate model of vehicle. The model has to be represented with appropriate mathematical formulation. Half-part models are usually preferred and used for 2D analysis as a combination of mass, spring and beam elements. This discrete model of the vehicle with finite degrees of freedom makes solution easier from the mathematical point of view. This assumption changes partial differential equations to the ordinary differential equations [1 and 2].

The main characteristic of the half part model is defined by three diagonal matrices. They are the mass $[m]$, stiffness $\left[k_{i}\right]$ and damping $\left[b_{i}\right]$ matrices which contain experimentally measured values [2].

$\left\{\mathbf{m}_{\mathbf{i}}\right\}_{\mathbf{D}}=\left\{m_{1}, I_{\mathrm{y} 1}, m_{2}, m_{3}, I_{\mathrm{y} 3}\right\}_{\mathrm{D}}=\{11475 ; 31149 ; 455 ; 1070 ; 466\}_{\mathrm{D}}$ $\left[\mathrm{kg}, \mathrm{kg} \cdot \mathrm{m}^{2}\right]$

$\left\{\mathbf{k}_{\mathrm{i}}\right\}_{\mathrm{D}}=\left\{k_{1}, k_{2}, k_{3}, k_{4}, k_{5}\right\}_{\mathrm{D}}=\{143716.5 ; 761256 ; 1275300 ; 2511360$; $2511360\}_{\mathrm{D}}[\mathrm{N} / \mathrm{m}]$

$\left\{\mathbf{b}_{\mathbf{i}}\right\}_{\mathbf{D}}=\left\{b_{1}, b_{2}, b_{3}, b_{4}, b_{5}\right\}_{\mathrm{D}}=\{19228,260197,2746,5494,5494\}_{\mathrm{D}}$ $[\mathrm{kg} / \mathrm{s}]$

\subsection{Description of the Interaction Model between the Tatra 815 and Soil}

In this article a numerical 2D model of the vehicle as well as of pavement are created using computer software ADINA. Computer software ADINA offers all options that are in demand. It offers to define contact pairs between the elements of vehicle that ensured the interaction between the pavement and the vehicle [1].

The computational model of the road is based on Kirchhoff theory of thin plates on a flexible substrate. For the purposes of numerical calculations the following composition of road layers was chosen:

CC I - cement concrete plate $h_{l}=240 \mathrm{~mm}, E_{l}=37500 \mathrm{MPa}$,

$v_{1}=0.20$

CA II - coated aggregate as Class II. $h_{2}=40 \mathrm{~mm}, E_{2}=4500 \mathrm{MPa}$, $v_{1}=0.21$

CS I - cement stabilization as Class I. $h_{3}=200 \mathrm{~mm}$,

$E_{3}=2000 \mathrm{MPa}, v_{1}=0.23$

PL - protective layer of gravel $h_{4}=250 \mathrm{~mm}, E_{4}=120 \mathrm{MPa}$,

$v_{1}=0.35$

SS - subsoil $h_{5}=\infty \mathrm{mm}, E_{5}=30 \mathrm{MPa}, v_{l}=0.35$

The pavement is modeled as a rigid surface. It is composed of the surface for acceleration (15m) and the surface for braking (15m) (see Fig. 2).

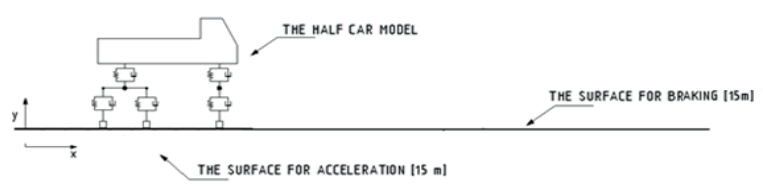

Fig. 2 The numerical model of interaction system

\subsection{Description of the Computing Software ADINA}

ADINA is a commercial engineering simulation software program which is used in industry and academia to solve structural, fluid, heat transfer, and electromagnetic problems. ADINA can also be used to solve multiphysics problems, including fluid-structure interactions and thermo-mechanical problems. ADINA is the acronym for Automatic Dynamic Incremental Nonlinear Analysis. The program consists of four core modules:

- ADINA Structures for linear and nonlinear analysis of solids and structures

- ADINA Thermal for analysis of heat transfer in solids and field problems

- ADINA CFD for analysis of compressible and incompressible flows, including heat transfer

- ADINA EM for analysis of electromagnetic phenomena.

These modules can be used fully coupled together to solve multiphysics problems, where the response of the system is affected by the interaction of several distinct physical fields (e.g. fluid-structure interaction, thermo-mechanical analysis, piezoelectric coupling, Joule heating, fluid flow-mass transfer coupling, electromagnetic forces on fluids and structures, etc.) [3].

\subsubsection{Principles of Numerical Solver}

An effective implicit time integration scheme was proposed for the finite element solution of nonlinear dynamics problems. Direct time integration is widely used in the finite element solutions of transient wave propagation problems. However, accurate solutions are difficult to obtain because of numerical dispersion and dissipation, resulting from period elongations and amplitude decays. In the solution of transient wave propagations, the errors from the spatial and temporal discretizations appear together and affect each other. Analyses of these errors have led to the use of linear combinations of consistent and lumped mass matrices. Another approach is to reduce the solution errors by evaluating the mass and stiffness matrices using modified spatial integration rules. Such schemes can improve the accuracy of solutions of multi-dimensional wave propagation problems when using certain elements and meshes.

We analyze the dispersion errors resulting from the spatial discretization coupled with the temporal discretization. We consider the Bathe method and the Newmark trapezoidal rule. For this purpose, we handle the solution obtained for the scalar wave governed by:

$\frac{\partial^{2} u}{\partial t^{2}}-c_{0}^{2} \nabla^{2} u=0$ 
where $u$ is the field variable and $c_{0}$ is the wave velocity. Here, body forces are not considered since we focus on the dispersion associated with the propagations of disturbances due to initial conditions. The associated finite element discretization gives

$\mathrm{MU}+\mathbf{c}_{0}^{2} \mathrm{KU}=\mathbf{0}$

where $K$ and $M$ are the stiffness and mass matrices, and for element $(m)$ with volume $V^{(m)}$

$$
\begin{aligned}
& \mathbf{M}^{(\mathbf{m})}=\int_{\mathbf{V}^{(\mathbf{m})}} \mathbf{H}^{(\mathbf{m})^{\mathrm{T}}} \mathbf{d} \mathbf{V}^{(\mathbf{m})} \\
& \mathbf{K}^{(\mathbf{m})}=\int_{\mathbf{V}^{(\mathbf{m})}}\left(\nabla \mathbf{H}^{(\mathbf{m})}\right)^{\mathrm{T}}\left(\nabla \mathbf{H}^{(\mathbf{m})}\right) \mathbf{d} \mathbf{V}^{(\mathbf{m})}
\end{aligned}
$$

Here, $H^{(m)}$ and $U$ are the element interpolation matrix and the nodal values of the solution, respectively. The matrices $M$ and $K$ in Eq. (3) are obtained by the usual summation process.

In the Bathe method, the following relations are employed

$$
\begin{aligned}
& { }^{t+\Delta t / 2} \dot{U}={ }^{t} \dot{U}+\left[\frac{\Delta t}{4}\right]\left({ }^{t} \ddot{U}+{ }^{t+\Delta t / 2} \ddot{U}\right) \\
& { }^{t+\Delta t / 2} U={ }^{t} U+\left[\frac{\Delta t}{4}\right]\left({ }^{t} \dot{U}+{ }^{t+\Delta t / 2} \dot{U}\right) \\
& { }^{t+\Delta t} \dot{U}=\frac{1}{\Delta t}{ }^{t}\left(U-\left[\frac{4}{\Delta t}\right]{ }^{t+\Delta t / 2} U+\frac{3}{\Delta t}{ }^{t+\Delta t} U\right) \\
& { }^{t+\Delta t} \ddot{U}=\frac{1}{\Delta t}{ }^{t}\left(\dot{U}-\left[\frac{4}{\Delta t}\right]^{t+\Delta t / 2} \dot{U}+\frac{3}{\Delta t}{ }^{t+\Delta t} \dot{U}\right)
\end{aligned}
$$

Using Eq. (3) at times $t, t+\Delta t / 2$ and $t+\Delta t$, where $t$ denotes the current time and $\Delta t$ the time step, with Eqs. (6)-(9), we obtain a linear multistep form of the Bathe method

$$
\begin{aligned}
& \left(72 M+8 c_{0}^{2} \Delta t^{2} K\right)^{t+\Delta t} U+\left(-144 M+5 c_{0}^{2} \Delta t^{2} K\right)^{t+\frac{\Delta t}{2}} \\
& U+\left(72 M+5 c_{0}^{2} \Delta t^{k} K\right)^{t} U=0
\end{aligned}
$$

Using the definition of the $C F L$ number, $=$, where $h$ is the 'characteristic length' of a finite element (or fundamental length used), Eq. (10) becomes

$$
\begin{aligned}
& (72 M+8 \gamma K)^{t+\Delta t} U+(-144 M+5 \gamma K)^{t+\frac{\Delta t}{2}} \\
& U+(72 M+5 \gamma K)^{t} U=0 \\
& \text { where } \gamma=C F L^{2} h^{2}[4] .
\end{aligned}
$$

\subsection{The Dynamic Analysis Results}

The vehicle passes on a pavement at a constant speed during the whole simulation. The used speed is 40,60 and $80 \mathrm{~km} / \mathrm{h}$.

The time step for simulation has a value $1 / 50$ of second. The following Fig. 3 shows the displacement in the pavement for variable speed.

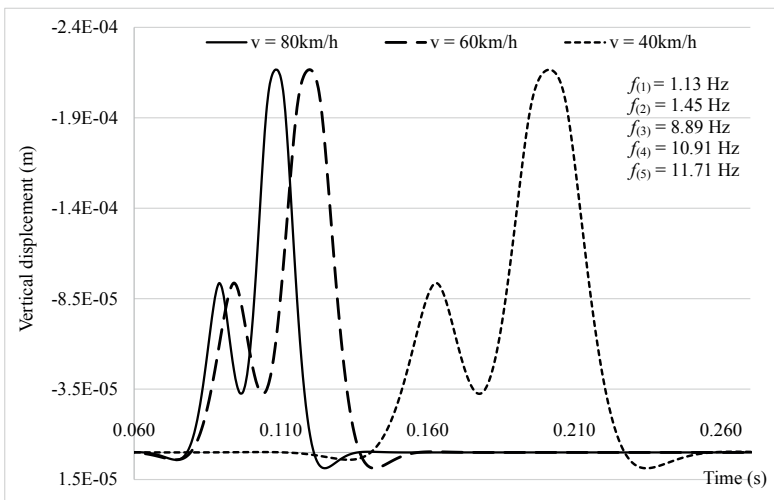

Fig. 3 The displacement on the pavement for variable vehicle speed with natural frequencies

\section{The Road and Soil Dynamic Response - M2}

The time response function obtained from model M1 for $60 \mathrm{~km} / \mathrm{h}$ is used as basic dynamic load for M2 model. This function was time shifted with step $\Delta \mathrm{t}=0.14 \mathrm{~s}$ corresponding to simulated vehicle model speed and road FE dimension $l=2 \mathrm{~m}$. The number of the dynamic load functions was 50 . Each function was step by step applied to nodes in the central line of the road upper surface layer. The example of the first $22 \mathrm{~m}$ dynamic load is shown in the Fig. 4.

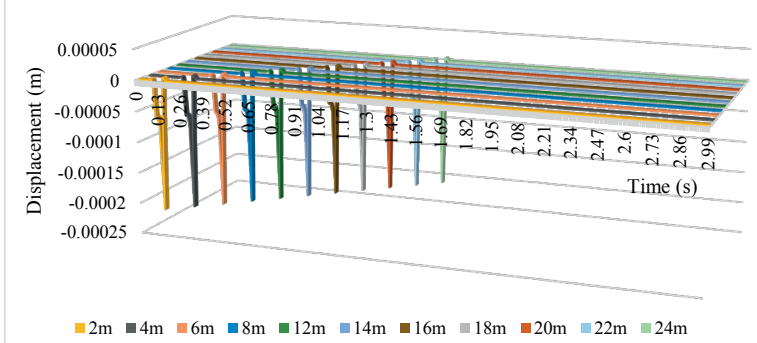

Fig. 4 The dynamic load example for the first 11 time functions

\subsection{Description of the Road-Soil Model}

The road-soil computing model is created in VisualFEA system. The reference part of the half space [5] used for roadsoil is created as a cuboid with length $100 \mathrm{~m}$. All finite elements are $3 \mathrm{D}$ solid type. Width of the model is $25 \mathrm{~m}$ and road layer width is $6 \mathrm{~m}$. The mechanical properties and thicknesses of created layers are summarized in Table 1. The mechanical properties of the road sublayers are averaged. Geological environment properties are the same as geological properties of the locality for in-situ measurement in [6]. Support of the M2 
model is only on the bottom surface of a rock soil layer. The colors in Table 1 correspond with colors on model M2, Fig. 5.

Geometric and material parameters of the M2 layers
\begin{tabular}{|l|r|r|r|r|}
\hline & & & & \\
Layer & \multicolumn{1}{|c|}{$\mathrm{E}$} & Poisson ratio & Unit weight & Thickness \\
\hline & $(\mathrm{MPa})$ & & $\left(\mathrm{kg} / \mathrm{m}^{3}\right)$ & $(\mathrm{m})$ \\
\hline Road layers & 12457 & 0.21 & 2186 & 0.48 \\
\hline Subsoil & 1500 & 0.15 & 1800 & 10 \\
\hline Rock soil & 15000 & 0.25 & 2600 & 10 \\
\hline
\end{tabular}

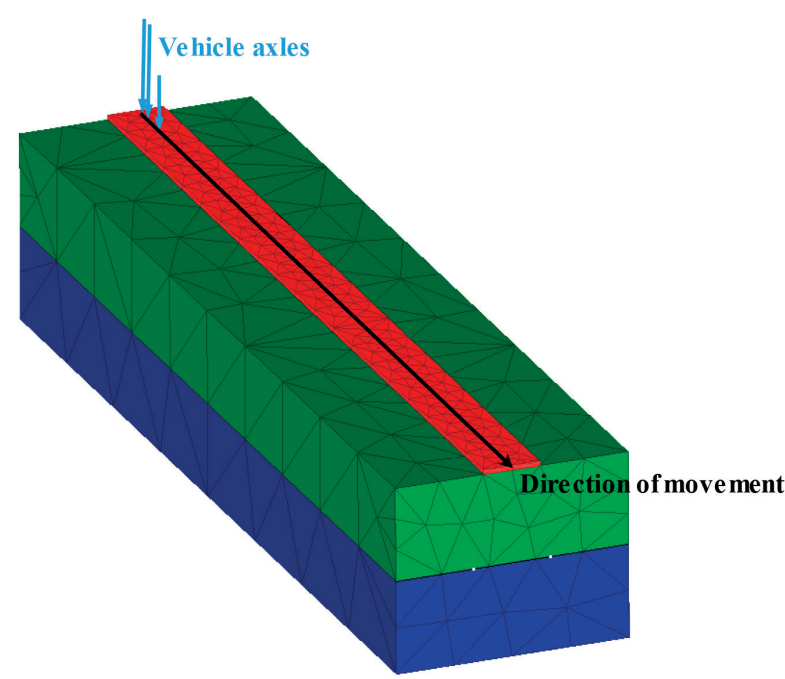

Fig. 5 The road-soil FEM model M2

\subsection{Description of the Visual FEA Software}

Visual FEA is innovative software for finite element (FE) analysis, which is an advanced technique to solve and analyze physical problems arising in many fields of science and engineering. This program is a full-fledged software integrated with ease-of-use but powerful functions for pre- and post-processing as well as for FE processing. Visual FEA has functions for studying FE analysis and it uses deformation variant of the FEM. The various computational aspects and concepts involved in FE modeling can be easily understood through computational simulation. Its preprocessing capability includes the most advanced 2 and 3-dimensional mesh generation techniques. The analysis can be divided into three phases [7]:

- Preprocessing - these functions are to create, edit and check the modeling data necessary for FE analysis. The data are constructed in a few steps: creation of boundary curves and surface primitives, mesh generation and data assignment
(Boundary condition, Element property, Load condition etc.),

- Processing - this phase is the kernel of FE analysis. Processing does not require user interaction and proceeds with various stages of computing element equations, assembling system equations, solving them, and executing other related computations,

- Postprocessing - Functions of this group are used for graphic visualization or further processing of the computed results of the analysis to facilitate their interpretation and understanding.

\section{The Results of the Dynamic Analysis and their Comparison with the Experiment}

The numerical simulation results of the Tatra 815 are presented for the point on the road edge (right and left are the same if it is symmetric) in $25 \mathrm{~m}$ distance from the start point $0 \mathrm{~m}$. The central point of M2 results are presented because there is minimal effect of mirrors [8]. Figure 6 shows the results in time domain.

The experimental measurement of the road dynamic response due to traffic seismicity was performed in 2008 as a part of the dissertation thesis research [6]. The measurement conditions were considered in the M2 numerical simulation. Only recordings in the point on the road surface were taken into account. In Figs. 7 and 8 are spectral characteristics of the vibration acceleration due to the Tatra 815 road response in vertical and horizontal directions. The average speed of vehicles was $60 \mathrm{~km} / \mathrm{h}$. The dashdot curve in Figs. 7 and 8 represents enveloping curve of results.

Figure 9 presents comparison between the experimental and numerical results. Owing to the fact that the experimental results in time domain are non-filterable, experimental verification is relevantly possible in a frequency domain only. The enveloping curve from the experiment overlaps with numerical PSD for vertical and horizontal directions.

\section{Conclusions}

Problems with the vibrations of civil and traffic structures due to technical seismicity resources are current. Soil-borne vibrations and their effects on civil structures can be solved theoretically (using FEM simulations) and can also be detected experimentally. This paper shows one of the simplified theoretical approaches to traffic seismicity vibration assessment. Both computing systems are useful tools for numerical simulations but each of them is more comfortable for another specialized analysis. Combination of these FEM systems has achieved interesting results but there is more than one precision deficient. Here are some of them: 


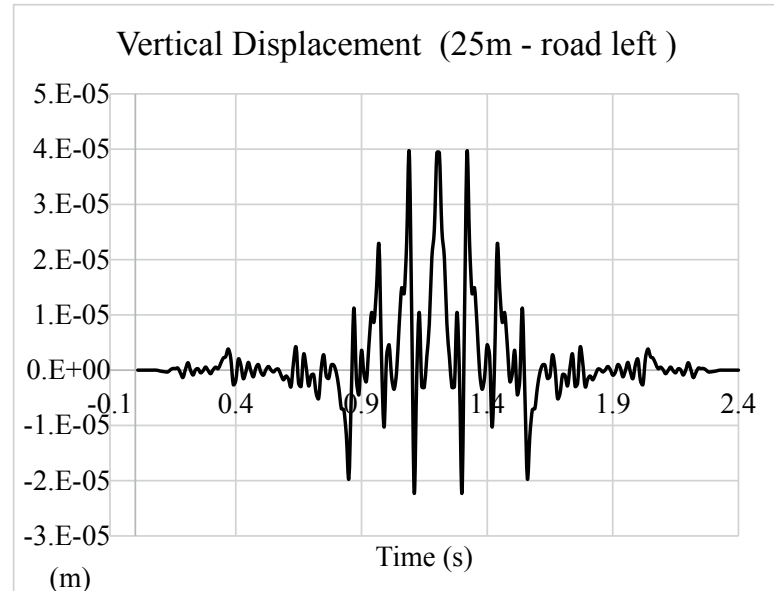

(m)

Vertical Vibration Velocity (25m - road left )

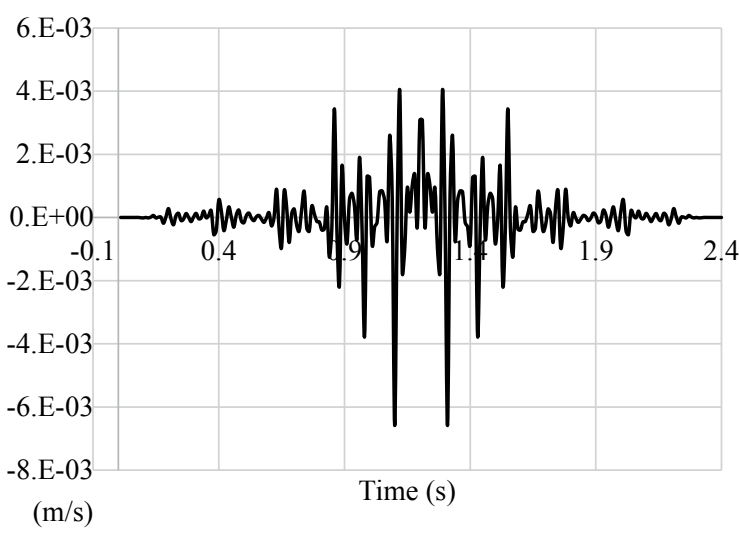

Vertical Vibration Acceleration (25m - road left )

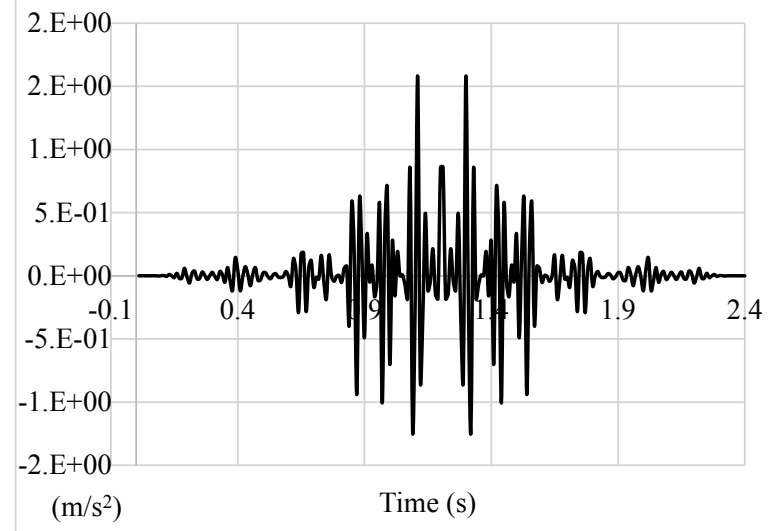

Horizontal Displacement (25m - road left )

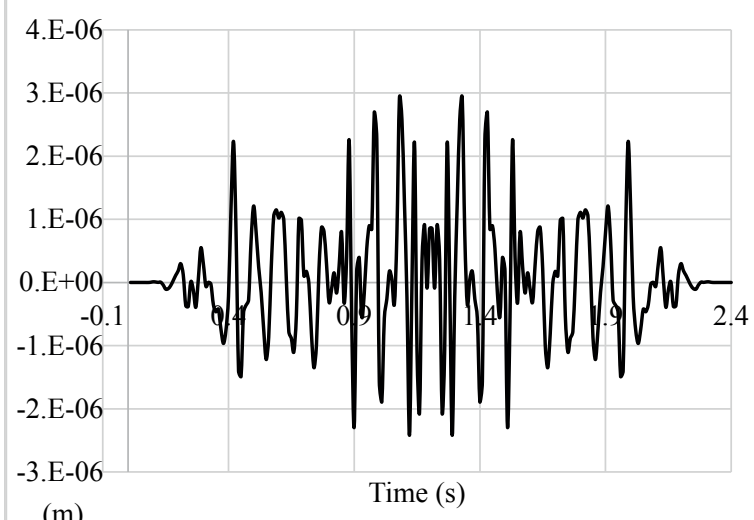

(m)

Horizontal Vibration Velocity (25m - road left)

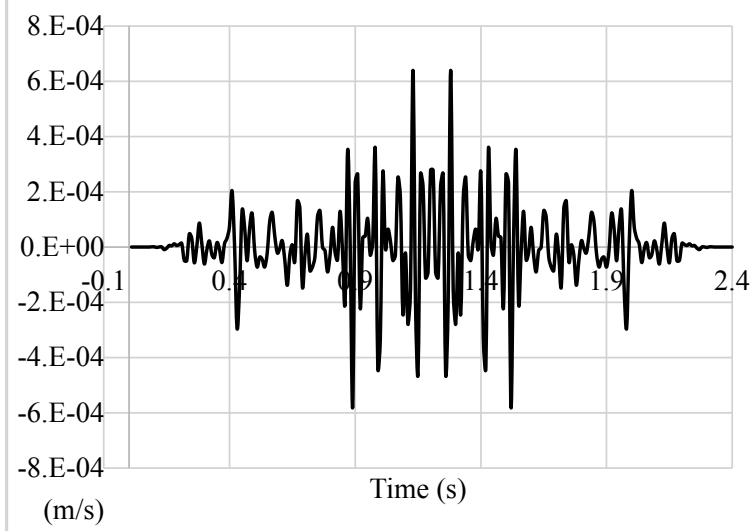

$(\mathrm{m} / \mathrm{s})$

Horizontal Vibration Acceleration (25m - road left)

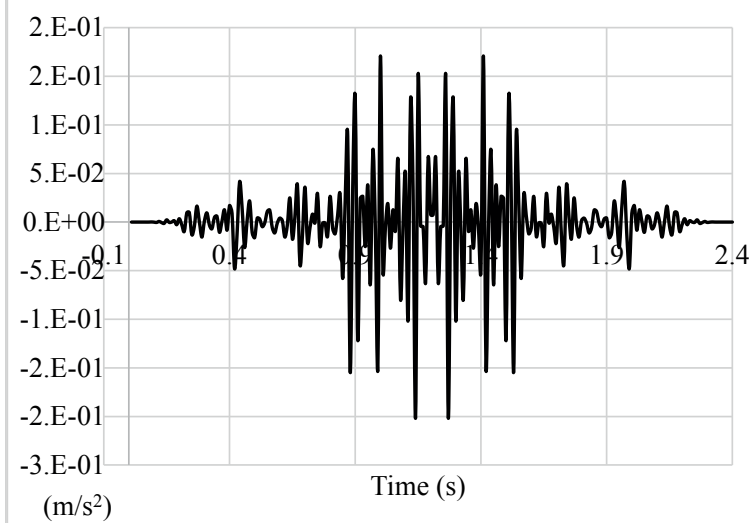

Fig. 6 The results of simulation in the time domain

- Live interaction between M1 and M2 is not possible in this approach.

- No unevenness was modeled in M1, therefore, vehicle excitation is not involved in the model.

- Only symmetric line of the vehicle movement is present.
Though, using this approach, significant results for the future discussion can be obtained:

- Average heavy-duty vehicle (similar to the Tatra 815) moving on the road with a low unevenness level generates only two impacts between the axles. This effect is verified by Fig. 9 


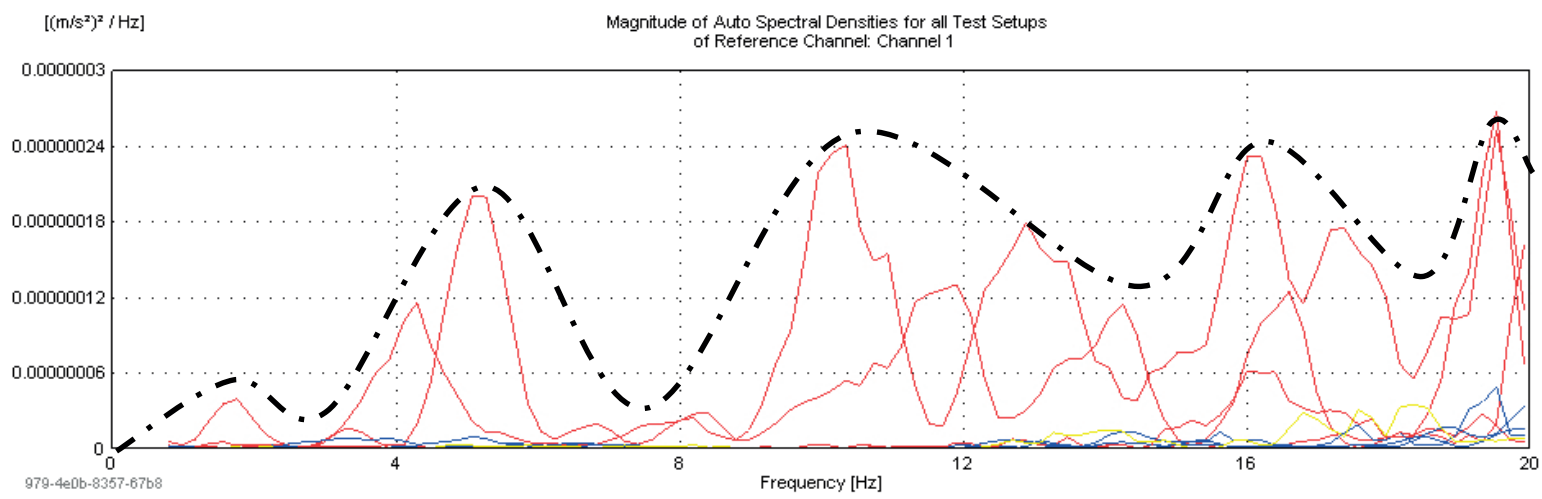

Fig. 7 Measured vertical Dynamic response at the edge of the road surface in frequency domain - vertical acceleration Power spectral density (PSD)

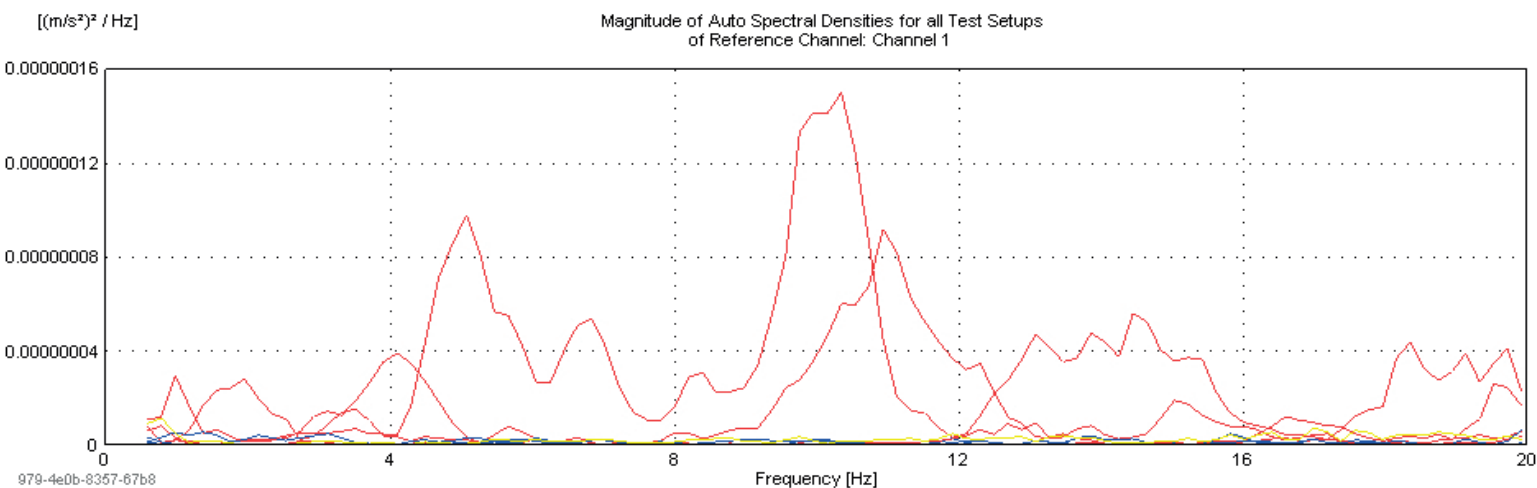

Fig. 8 Measured vertical Dynamic response at the edge of the road surface in frequency domain - horizontal acceleration Power spectral density (PSD)
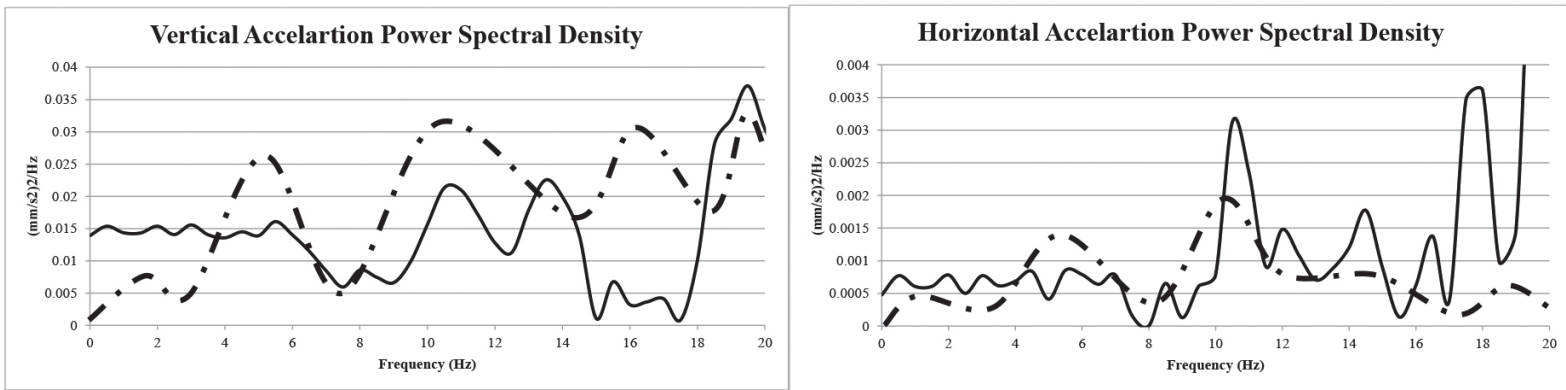

Fig. 9 The acceleration Power Spectral Density comparison - numerical and experimental

where a frequency band from 8 to $12 \mathrm{~Hz}$ shows similar peaks. The vehicle speed of about $60 \mathrm{~km} / \mathrm{h}$ with the axle distance similar to that of the Tatra 815 generates just the frequency of $10 \mathrm{~Hz}$.

- It is possible to add some simple civil structures into the model M2 and in many cases vibration effects on these structures can be assessed.
The results obtained by FEM simulation are in relatively good accordance with the experiment. It is necessary to know the basic parameters of the soil for a complex computing model. If we want to estimate the effects of technical seismicity, the most efficient is to use theoretical and experimental approaches [9]. 


\section{References}

[1] DANIEL, L., VALASKOVA, V., KORTIS, J.: Numerical Simulation of Moving Vehicle across the Obstacle. Civil and Environmental Engineering, vol. 10, No. 2, 108-112, ISSN 1336-5835, 2014.

[2] MARTINICKA, I.: Calculation of Natural Frequencies and Vibration Shapes its own Computational Models of Vehicles, Land Communications and Tracks, vol. 6, No. 1-2, 41-50, 2010, ISSN 1336-7501.

[3] ADINA R \& D, Official Website.

[2] PERSSON, P., A., HOLMBERG, R., LEE, J.: Rock Blasting and Explosives Engineering. Boca Raton, Fla.: CRC Press, 1993, 560, ISBN 0-8493-8978-X.

[4] GUNWOO, N., SEOUNGHYUN, H., BATHE, K., J.: Performance of an Implicit Time Integration Scheme in the Analysis of Wave Propagations, Computers and Structures, 123, 2013, 93-105.

[5] BENCAT, J., STYPULA K.: Buildings Structure Response Due to Railway Traffic. Communications - Scientific Letters of the University of Zilina, vol. 15, No. 2, 2013, 41-48 (Civil-Comp Proceedings, 102. ISSN 1759-3433), ISSN 1335-4205.

[6] PAPAN, D.: Spectral Characteristics of the Load and Response of Bridges Due to Technical Seismicity, Thesis, University of Zilina, 2008.

[7] http://www.visualfea.com/manual-normal/index_online.html, Manual of the computing system VisualFEA.

[8] PAPANOVA, Z., PAPAN, D., KORTIS, J.: Microtremor Vibrations in the Soil Experimental Investigation and FEM Simulation, Communications - Scientific Letters of the University of Zilina, vol. 16, No. 4, 2014, 41-47, ISSN 1335-4205.

[9] MORAVCIK, M.: Analysis of Vehicle Bogie Effects on Track Structure - Non-Stationary Analysis of Dynamic Response. Communications - Scientific Letters of the University of Zilina, vol. 13, No. 3, 2011, 33-40, ISSN 1335-4205. 